\title{
Band 3 Protein Function in Teleost Fish Erythrocytes: Effect of Oxygenation-Deoxygenation
}

\author{
A. RUSSO ${ }^{1}$, E. TELLONE ${ }^{1}$, S. FICARRA ${ }^{1}$, B. GIARDINA ${ }^{2}$, E. BELLOCCO ${ }^{1}$, G. LAGANA $^{, 1}$, \\ U. LEUZZI ${ }^{1}$, A. KOTYK ${ }^{3}$, A. GALTIERI ${ }^{1}$
}

${ }^{1}$ Department of Organic and Biological Chemistry, University of Messina, Italy, ${ }^{2}$ Institute of Biochemistry and Clinical Biochemistry and "Centro C.N.R. per lo Studio della Chimica dei Recettori", Catholic University of Rome "Sacro Cuore", Rome, Italy, ${ }^{3}$ Institute of Physiology, Academy of Sciences of the Czech Republic, Prague, Czech Republic

Received December 12, 2006

Accepted January 16, 2007

On-line available February 8, 2007

\begin{abstract}
Summary
During vertebrate evolution, structural changes in red blood cells (RBC) and hemoglobin ( $\mathrm{Hb}$ ), have probably resulted in the importance of blood carbon dioxide transport. The chloride/bicarbonate exchange across the RBC membrane, which is an integral part of the blood $\mathrm{CO}_{2}$ transport process in vertebrates, has been examined on two different species of teleost fish, Euthynnus alletteratus and Thunnus thynnus, at several oxygenation states of erythrocyte HOS (high-oxygenation state, about $90 \%$ of saturation) and LOS (low-oxygenation state, about $15 \%$ of saturation). The results were compared with those observed in human RBC under the same experimental conditions and with the chicken (Gallus gallus) erythrocytes, which have particular modifications at the $\mathrm{N}$-terminus of the band 3 protein (B3). In fish the kinetic measurements have shown a different anion transport in several oxygenation states of erythrocytes, indicating that also at lower levels of vertebrate evolution there exists a modulation of the anionic flow affected by oxygen. The functional correlation of anion transport to changes of parts of the hemoglobin sequence responsible for alterations in the interactions with the cytoplasmic domain of band 3 protein (cdb3) allowed us to suggest a hypothesis about fish physiology. The highest values of kinetic measurements observed in fish have been attributed to the metabolic need of the RBC in response to the removal of $\mathrm{CO}_{2}$ that in teleosts is also of endogenous origin.
\end{abstract}

\section{Key words}

Erythrocyte - Hemoglobin - Band 3 protein $\bullet$ Anion transport • Oxygenation-deoxygenation cycle

\section{Corresponding author}

A. Kotyk, Institute of Physiology, Academy of Sciences of the Czech Republic, 14220 Prague 4, Czech Republic. E-mail: kotyk@biomed.cas.cz

\section{Introduction}

The complex function of the transport of oxygen and carbon dioxide in blood is closely associated with the electrolytic and acid-base equilibrium of the red blood cell, markedly depending on membrane permeability and the function of proteins contained in it (Thomas and Egee 1998).

Moreover, various physical and functional characteristics of the erythrocyte (including glycolysis, pentose-phosphate cycle, ion fluxes and cell deformability) show a strong dependence on the state of oxygenation of hemoglobin, whose molecular mechanism involves the interaction with another abundant protein present at the membrane, viz. the band 3 protein.

While the $\mathrm{Hb}$ carries out the function of oxygen transport from lungs or gills to the tissues, the band 3 protein carries out the electrically neutral exchange of chloride and bicarbonate anions between the inside and the outside of the red blood cell. The active form of the band 3 protein is a dimer in which each monomer, represented by 920 amino acids is subdivided in two fundamental regions: a hydrophobic region that crosses the membrane with 12-14 $\alpha$-helices and a cytoplasmic hydrophilic region (cdb3) distinct in its turn in two domains, N-terminal and C-terminal. The integral membrane domain represents the protein portion involved in the function of an ion channel; the cytoplasmic domain connects binding with various intraerythrocytic proteins, among them the cytoskeletal proteins (ankyrin, band 4,1 
and band 4,2) and carbonate dehydratase to the extreme C-terminus (Bruce et al. 2003), the glycolytic enzymes (Low 1986, Harris et al. 1990, Low et al. 1993) and hemoglobin (Cassoly 1983, Chetrite and Cassoly 1985) to the N-terminus.

In particular, $\mathrm{Hb}$ binds to $\mathrm{cdb} 3$ through $\beta$-chains; this binding is mostly of electrostatic nature and is influenced by the state of oxygenation of the erythrocyte. The interaction causes a sort of bivalent modulation, decreasing the hemoglobin affinity for oxygen and changing the $\mathrm{HCO}_{3}{ }^{-} / \mathrm{Cl}^{-}$flux, probably due to a kind of steric hindrance exercised by $\mathrm{Hb}$ on the intermembrane channel (Galtieri et al. 2002). The binding between band 3 and hemoglobin takes place at the level of the first extremely acid 11 amino acid residues of the N-terminal portion of the band 3 cytoplasmic domain. This portion fits perfectly into the central cavity of the hemoglobin molecule at the level of 2.3-biphosphoglycerate (BPG) binding cleft involving all the basic residues responsible for binding with phosphate (that is Val1, His2, His143 and Lys 82) beyond to Arg104 residue characteristic of the binding with cdb3. Some glycolytic enzymes interact also with the N-terminal part of the band 3 and their binding causes a kind of competition with the $\mathrm{Hb}$ for the same site. Since band 3 coordinates the transmembrane anion exchange $\left(\mathrm{HCO}_{3}{ }^{-} / \mathrm{Cl}^{-}\right)$and the glycolytic enzymes govern the metabolic pathway in the erythrocyte, it follows that $\mathrm{Hb}$ can work as a transducer, through its T-R transition, modulating the metabolism of the red blood cell and the anion exchange in an oxygen-dependent way (Giardina et al. 1995, Galtieri et al. 2002).

The question then naturally arises whether vertebrate $\mathrm{Hbs}$ at the lowest evolutionary level can have evolved an oxygen-dependent affinity for their respective cdb3, assuming that in the erythrocyte the evolution of a regulatory mechanism modulating some fundamental functions is desirable and predictable. Arguments against such hypothesis include the fact that in vertebrates the object of study is the N-terminus of band 3 sequence, which is not highly conserved, while supporting data indicate that all the cdb3 known are polyanionic and that many deoxygenated $\mathrm{Hb}$ (deoxyHb) of vertebrates show high affinity for polyanions, such as BPG, IPP or ATP (Weber et al. 2004).

Since it is known that many evolutionary changes are the result of amino acid replacements in biologically important proteins, starting with the premise that the erythrocytes carry out anion exchange through band 3 and that their Hbs as well as the type of organic phosphates in the red blood cell are different, we performed a kinetic study of $\mathrm{HCO}_{3}{ }^{-} / \mathrm{Cl}^{-}$exchange. The aim of our work was to verify if in species with brachial respiration (first level of vertebrate evolution), with nucleated red blood cells and an oxygen-dependent metabolism, the function of band 3 is modulated by the pressure of oxygen as we have shown earlier (Galtieri et al. 2002) in species with pulmonary respiration (last stage of vertebrate evolution), with anucleate erythrocytes and with metabolism involving the central carbohydrates in an absolutely oxygen-independent way. Moreover, we wish to show whether the energetic (ATP) or the reducing (NADPH) metabolic response in a fish red blood cell, remarkably more complex (structurally and functionally) than that of fully developed vertebrate (mammalian) one are more important. In fact, in fish erythrocytes oxygen is not only an "active" transit molecule, but also the final protagonist with an effective use in electron transport (producing $\mathrm{H}_{2} \mathrm{O}$ and ATP) and that is fed from the Krebs cycle generating endogenous carbon dioxide, which is the "substrate" of the band 3 protein.

\section{Methods}

\section{Material}

All reagents were from Sigma-Aldrich (St. Louis, MO, USA). Human erythrocyte samples were collected from informed healthy volunteers aged 30-50 years under the declaration that they had avoided any drug treatment at least one week before sample collection. Fish and chicken blood was obtained from local fish farm and slaughterhouse, respectively.

\section{Preparation of red blood cells}

Heparinized blood samples were washed three times with iso-osmotic $\mathrm{NaCl}$ solution. During washings the white blood cells were discarded from the pellet. After washing the red blood cells were resuspended (hematocrit $3 \%$ ) in the incubation buffer (35 $\mathrm{mM}$ $\mathrm{Na}_{2} \mathrm{SO}_{4}, 90 \mathrm{mM} \quad \mathrm{NaCl}, 25 \mathrm{mM}$ HEPES [N-(2hydroxyethyl)-piperazine- $N$-2-ethanesulfonic acid], 1.5 $\mathrm{mM} \mathrm{MgCl}_{2}$ ), adjusted to $\mathrm{pH} 7.4$ or 7.3 and $310 \pm 20$ mOsmol per $\mathrm{kg}$, measured by an Osmostat OM-6020 apparatus (Daiichikagakuco, Kyoto, Japan).

In experiments performed on deoxygenated erythrocytes samples were submitted to cycles of deoxygenation in vacuo and nitrogen (ultrapure) saturation at a pressure of 760 Torr. This treatment allowed us to obtain different levels of deoxygenation 


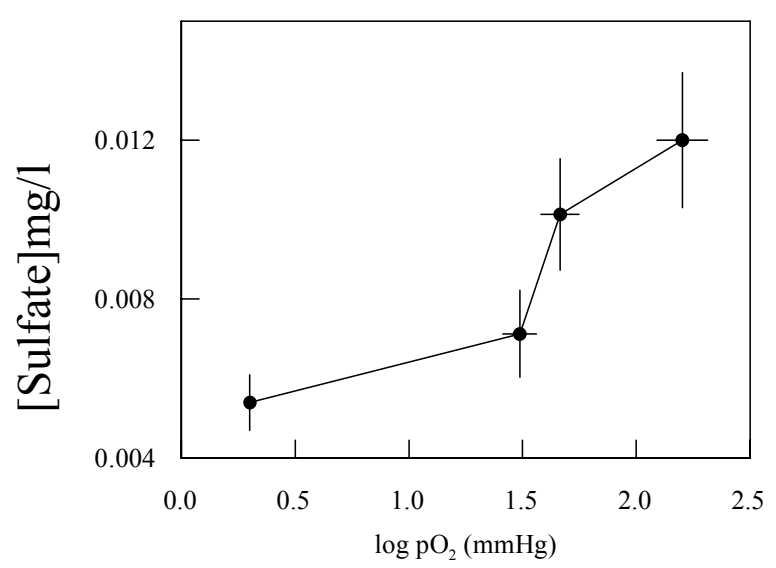

Fig 1. Rates of sulfate influx determined in human erythrocytes under different oxygen pressure. For experimental conditions see Methods.

(from $15 \%$ to $90 \%$ ), which were checked by determining hemoglobin saturation spectrophotometrically (Beckman DU 70 spectrophotometer) using the millimolar absorptivities reported by Zijlstra et al. (1991).

The buffer used to prepare deoxygenated erythrocytes was by $0.1 \mathrm{pH}$ unit lower than that used for oxygenated erythrocytes, in order to compensate for the Haldane effect occurring during the deoxygenation step (Labotka et al. 1984). Thus, after the deoxygenation procedure, the oxygenated and deoxygenated samples had an external $\mathrm{pH}$ differing by no more than $0.03 \mathrm{pH}$ units.

\section{Kinetic measurements}

Cells were incubated in the above incubation buffer at $25^{\circ} \mathrm{C}$, under different experimental conditions. At several time intervals, 10 micromoles of the stopping medium SITS (4-acetamido-4'-isothiocyanostilbene-2,2'disulfonic acid) were added to each test tube containing $5 \mathrm{ml}$ of the red blood cell suspension. Cells were then separated from the incubation medium by centrifugation (J2-HS Centrifuge, Beckman, Palo Alto, CA, USA) and washed three times at $4{ }^{\circ} \mathrm{C}$ with a sulfate-free medium to remove sulfate anions trapped outside. After the last washing packed cells were lysed with perchloric acid (4\%) and distilled water (2.8 $\mathrm{ml}$ final volume). The lysates were centrifuged for $10 \mathrm{~min}$ at $4000 \times g\left(4{ }^{\circ} \mathrm{C}\right)$ and membranes were separated from the supernatant. Sulfate ions were precipitated from the supernatant by adding $1 \mathrm{ml}$ of glycerol/distilled water mixture (1:1, $\mathrm{V} / \mathrm{V}), 0.5 \mathrm{ml}$ of $4 \mathrm{M} \mathrm{NaCl}$ and $1 \mathrm{M} \mathrm{HCl}, 0.5 \mathrm{ml}$ of $1.23 \mathrm{M}$ $\mathrm{BaCl}_{2}$ in order to obtain a homogeneous barium sulfate precipitate. The absorbance of this suspension was

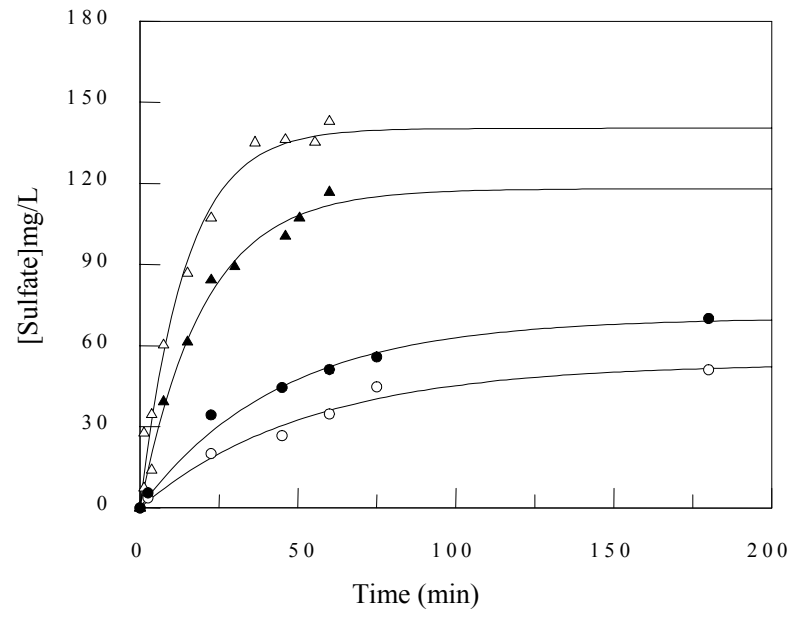

Fig. 2. Sulfate concentration $(\mathrm{mg} / \mathrm{l})$ determined in red blood cell lysates at different incubation times. Results of a typical experiment performed by incubating Thunnus thynnus (closed symbols) and Euthynnus alletteratus (open symbols) erythrocytes under high (triangles) and low (circles) oxygen pressure. Curves were obtained by fitting experimental data with $C(t)=C_{\infty}\left(1-\mathrm{e}^{-k t}\right)$. For further experimental data see Methods.

measured at 350-425 $\mathrm{nm}$.

Using a calibrated standard curve, obtained by measuring the absorbance of suspensions prepared from solutions containing known sulfate amounts, the sulfate concentration was determined (Romano et al. 1998). Experimental data of sulfate concentration as a function of time incubation were analyzed by best fitting procedures according to the following equation:

$C(t)=C_{\infty}\left(1-\mathrm{e}^{-k t}\right)$

where $C(t)$ represents sulfate concentration at time $t, C_{\infty}$ the intracellular sulfate concentration at equilibrium, and $k$ the rate constant of sulfate influx.

\section{Results}

The activity of anion exchange operating from band 3 appears in a marked manner in the oxygenation state of erythrocyte (Fig. 1), where it is represented as the kinetics of flux measured in the human red blood cells at several oxygen pressures. Averages of rate constant values determined for the sulfate influx in the oxygenated erythrocytes (HOS, high-oxygenation state, about $90 \%$ saturation) and deoxygenated ones (LOS, lowoxygenation state, about $15 \%$ saturation) indicate a remarkable increase of flux when the red blood cell passes from LOS to HOS state (rate constant from 0.005 to $0.012 \mathrm{~min}^{-1}$ ). 
In order to exclude the contribution of other transport systems influenced by oxygen pressure, we carried out a set of experiments on red cells pretreated with SITS, a specific inhibitor of band 3 activity. Under these experimental conditions no sulfate transport was observed.

Since teleost fish possess band 3 protein copies like that found in human anucleate erythrocytes and nothing is known about the oxygen influence on the antiport $\mathrm{Cl}^{-} / \mathrm{HCO}_{3}{ }^{-}$dynamics, we performed a series of experiments on the kinetics of the anionic flux in the red blood cells of two teleost fish species (northern bluefinned tuna Thunnus thynnus and Atlantic little tuna Euthynnus alletteratus), belonging to the family Scombriae) because in nucleated fish erythrocytes different mechanisms of ion transport are highly sensitive to the degree of oxygenation and to the $\mathrm{Hb}$ conformation (Motais et al. 1987, Jensen 1990) and that we already know the functional property of the hemoglobins from the two selected species (data not published). The results are shown in Fig. 2 where it is possible to observe that the rate of sulfate influx inside the $\mathrm{RBC}$ is similar in both species under conditions of high oxygen saturation (rate constant $0.242 \mathrm{~min}^{-1}$ for T. thynnus and $0.286 \mathrm{~min}^{-1}$ for E. alletteratus) or of low oxygen saturation (rate constant $0.148 \mathrm{~min}^{-1}$ and $0.115 \mathrm{~min}^{-1}$, respectively). From a direct comparison with the anion transport kinetics in human red blood cells it should be noted that the anion flux is remarkably higher and that HOS and LOS erythrocyte states, also in this case, influence the band 3 protein activity although in a less marked way. In this respect, the results shown in Table 1 in human $\mathrm{RBC}$ point to a decrease (approximately $60 \%$ ) of anion exchange when the experiments were performed at low oxygen pressure, while in fish red blood cells the passage from the HOS to LOS state brought about a smaller flux reduction (approximately $40 \%$ ).

This different influence of oxygen on the band 3 protein functionality could be due to the presence in fish erythrocytes of an $\mathrm{Hb}$ partially replaced in the binding pocket with cdb3. It would result in the weakness of the $\mathrm{Hb}-\mathrm{B} 3$ bond which would promote a lower modulation of the oxygen transporter molecule on the band 3 activity and therefore a lower sensitivity to oxygen pressure.

In order to show the effective role of the $\mathrm{Hb}$ cdb3 interaction we carried out experiments on sulfate transport kinetics in chicken erythrocytes, which are known to possess a modified cdb3, lacking the site of glycolytic enzymes (Jay 1983). The experiments
Table 1. Rates of sulfate transport measured in oxygenated and deoxygenated human and fish red blood cells.

\begin{tabular}{lll}
\hline Species & \multicolumn{2}{l}{ Rate constant $\left(\mathbf{m i n}^{-\mathbf{1}}\right)$} \\
\hline & Oxygenated & Deoxygenated \\
Homo sapiens & 0.0120 & 0.0052 \\
Thunnus thynnus & 0.242 & 0.148 \\
Euthynnus alletteratus & 0.286 & 0.115 \\
\hline
\end{tabular}

performed on the sulfate transport in this case did not indicate meaningful differences at the various oxygen saturations $\left(0.07 \mathrm{~min}^{-1}\right)$.

\section{Discussion}

We have shown here that in the erythrocytes of two teleost fish Thunnus thynnus and Euthynnus alletteratus the sulfate transport carried out by band 3 protein is closely linked to oxygen pressure. The anion flux through the membrane was decreased bz about $40 \%$ in both species in LOS erythrocytes (Fig. 2, Table 1); a similar result (decrease of approximately $60 \%$ ) was obtained in human red blood cells under the same experimental conditions (Fig. 1, Table 1). This finding suggests the presence of a regulatory mechanism for the anion transport at the early stages of vertebrate evolution, like that observed in the fully developed vertebrates. We assumed that the different activity of band 3 in HOS and LOS state was connected with the conformational transition of $\mathrm{Hb}(\mathrm{T}-\mathrm{R})$ due to oxygen pressure. Although direct evidence of any functional communication between the cdb3 binding site and the anion transport site cannot be established, all data obtained in this work can be rationalized on the basis that $\mathrm{cdb} 3 /$ deoxy-Hb binding influences the anion transport more than the cdb3/oxy-Hb does (Walder et al. 1984). Since $\mathrm{T}-\mathrm{Hb}$ has a higher affinity for cdb3 than R-Hb, a gradual increase of $\mathrm{Hb}$ bound to band 3 protein and consequently an increment of structural hindrance would take place on passing from HOS to LOS. The hindrance caused by deoxy-Hb on the band 3 channel justifies the reduction of the anion transport found in the deoxygenated erythrocytes. It is thus probable that the small difference of the kinetics of chloride exchange observed at several oxygenation states in fish red blood cells compared to that found in human ones, is due to a different interaction between $\mathrm{Hb}$ and band 3 , as a consequence of a series of amino acid 
replacements in teleost fish $\mathrm{Hb}$ (Weber 2000). In fact, the primary structure of these $\mathrm{Hbs}$ is characterized by a reduced presence of basic residues compared with human $\mathrm{Hb}$, just to the level of the binding site with $\mathrm{cdb} 3$. In particular, both $\beta$-chains show replacements Glu/Asp $\beta 2$ $\rightarrow$ His and $\operatorname{Arg} \beta 143 \rightarrow$ His involved in the binding with BPG, and the replacement Gln $\rightarrow$ Proß5 (Rodewald et al. 1987). The replacement in $\beta 2$ brings about the disappearance of two positive charges in the anionic pocket that, if it is stereochemically adapted to the interaction with ATP (physiological cofactor of fish, with less negative charges than BPG), weakens the positive charge cluster present on the $\mathrm{Hb}$ molecule, useful in the electrostatic interaction with cdb3. Moreover, the affinity constant between $\mathrm{cdb} 3$ and teleost $\mathrm{Hb}$ is further reduced by the $\beta 5$ replacement where a glutamine residue is changed to proline. This substitution that was evidenced also in many other species, such as whale, bat and reindeer, could cause a misfolding of the $\alpha$-helix, with a consequent variation of the binding stoichiometry between $\mathrm{cdb} 3$ and $\mathrm{Hb}$ (Giardina et al. 1990, Corda et al. 2003).

All these factors would contribute to weakening the binding between fish $\mathrm{Hb}$ and $\mathrm{cdb} 3$, so the reduced difference of the anion exchange through the membrane between oxygenated and deoxygenated RBC could be the consequence of a reducing and easily removable hindrance of the deoxy- $\mathrm{Hb}$ on the anionic channel. Arguments in support of this view rely on experiments performed with chicken erythrocytes, in which no differences in the band 3 activity between the HOS and LOS states were found. This finding should be linked to the absence in chicken cdb3 of the binding site for glycolytic enzymes and, therefore, to missing interaction between deoxy- $\mathrm{Hb}$ and the band 3 protein.

From a physiological and evolutionary point of view the differences found between fish and human $\mathrm{HCO}_{3}{ }^{-} / \mathrm{Cl}^{-}$exchange could be related to the energetic requirements of their red blood cells. In fact, human erythrocytes lacking mitochondria derive their energy from the anaerobic metabolism nearly completely dependent on glycolysis and the pentose phosphate shunt. This involves the need of a fine and efficient metabolic modulation of glucose-6-phosphate carried out through interaction between hemoglobin and band 3 protein. Bird and ectothermic vertebrate erythrocytes, in contrast, rich in mitochondria and mainly oriented toward aerobic metabolism, can respond to their metabolic requirements through a less marked $\mathrm{Hb}$-cdb3 interaction (Wang et al. 1994). In this regard, it is significant to note that the weak $\mathrm{Hb}$-cdb3 bond in teleost fish $\mathrm{RBC}$ allows an early activation of the pentose phosphate way toward lower oxygen concentrations than in human erythrocytes. In fact, the glycolytic enzyme binding sites will then slow down the glycolytic pathway and glucose-6-phosphate will enter in the pentose phosphate pathway. Consequently, the stronger production of reducing power will also allow a more effective cell defence against the free radicals derived from the direct use of oxygen also through oxidative phosphorylation. Likewise, the reducing power is necessary to increase the typical biosynthetic ways of a nucleate erythrocyte that can much more advantageously use aerobic metabolism with a higher production of adenosine triphosphate (18 times) than the anucleate one. The reduced glucose-6-phosphate use in the Embden-Meyerhof pathway does not decrease the oxygen release because the physiological modulator of fish hemoglobin is ATP, an organic phosphate more easily produced from the aerobic metabolism. Added to this metabolic picture we found: an increase of anionic exchange activity across the band 3 protein, certainly due to the presence in the cell of aerobic metabolism. The high $\mathrm{HCO}_{3}{ }^{-} / \mathrm{Cl}^{-}$flux observed in teleosts could be correlated to the need for a more efficient transport of $\mathrm{CO}_{2}$ that is not only of exogenous origin (tissue metabolism) but is also produced in an endogenous way by aerobic metabolism of carbon dioxide. In fact, it is known that there is an increased presence of $\mathrm{CO}_{2}$ in fish erythrocytes (compared to anucleate $\mathrm{RBC}$ ) partly due to exogenous origin but mainly due to the effectivity of the Krebs cycle, that leads to the necessity to expel the excess $\mathrm{CO}_{2}$, which is confirmed by the stronger activity of band 3 protein.

\section{Conflict of Interest}

There is no conflict of interest.

\section{References}

BRUCE LJ, BECKMANN R, RIBEIRO ML, PETERS LL, CHASIS JA, DELAUNAY J, MOHANDAS N, ANSTEE DJ, TANNER MJ: A Band 3-based macrocomplex of integral and peripheral proteins in the red cell membrane. Blood 101: 4180-4188, 2003. 
CASSOLY R: Quantitative analysis of the association of human hemoglobin with the cytoplasmic fragment of Band 3 protein. J Biol Chem 258: 3859-3864, 1983.

CHETRITE G, CASSOLY R: Affinity of hemoglobin for the cytoplasmic fragment of human erythrocyte membrane band 3. Equilibrium measurements at physiological $\mathrm{pH}$ using matrix-bound proteins: the effects of ionic strength, deoxygenation and of 2,3-diphosphoglycerate. J Mol Biol 185: 639-644, 1985.

CORDA M, TAMBURRINI M, DE ROSA MC, SANNA MT, FAIS A, OLIANAS A, PELLEGRINI M, GIARDINA B, DI PRISCO G: Whale (Balaenoptera physalus) haemoglobin: primary structure, functional characterisation and computer modelling studies. Comp Biochem Physiol B 134: 53-62, 2003.

GALTIERI A, TELLONE E, ROMANO L, MISITI F, BELLOCCO E, FICARRA S, RUSSO A, Di ROSA D, CASTAGNOLA M, GIARDINA B, MESSANA I: Band-3 protein function in human erythrocytes: effect of oxygenation-deoxygenation. Biochim Biophys Acta 1564: 214-218, 2002.

GIARDINA B, BRIX O, COLOSIMO A, PETRUZZELLI R, CERRONI L, CONDO' G: Interaction of hemoglobin with chloride and 2,3-biphosphoglycerate. A comparative approach. Eur J Biochem 194: 61-65,1990.

GIARDINA B, MESSANA I, SCATENA R, CASTAGNOLA M: The multiple functions of hemoglobin. Crit Rev Biochem Mol Biol 30: 165-196, 1995.

HARRIS SJ, WINZOR DJ: Interaction of glycolytic enzymes with erythrocyte membranes. Biochim Biophys Acta 1038: 306-314, 1990.

JAY DG: Characterization of the chicken erythrocyte anion exchange protein. J Biol Chem 258: 9431-9436, 1983.

JENSEN FB: Nitrite and red cell function in carp: control factors of nitrite entry, membrane potassium ion permeation, oxygen affinity and methaemoglobin formation. J Exp Biol 152: 149-166, 1990.

LABOTKA RJ: Measurement of intracellular $\mathrm{pH}$ and deoxyhemoglobin concentration in deoxygenated erythrocytes by phosphorus-31 nuclear magnetic resonance. Biochemistry 23: 5549-5555, 1984.

LOW PS: Structure and function of the cytoplasmic domain of band 3: center of erythrocyte membrane-peripheral protein interactions. Biochim Biophys Acta 864: 145-167, 1986.

LOW PS, RATHINAVELU P, HARRISON ML: Regulation of glycolysis via reversible enzyme binding to the membrane protein, Band 3. J Biol Chem 268: 14627-14631, 1993.

MOTAIS R, GARCIA-ROMEU F and BORGESE F: The control of $\mathrm{Na}^{+} / \mathrm{H}^{+}$exchange by molecular oxygen in trout erythrocytes. A possible role of hemoglobin as a transducer. J Gen Physiol 90: 197-207, 1987.

RODEWALD K, OBERTHUR W, BRAUNITZER G: Homeothermic fish and hemoglobin: primary structure of the hemoglobin from bluefin tuna (Thunnus thynnus, Scromboidei). Biol Chem Hoppe Seyler 368: 795-805,1987.

ROMANO L, PERITORE D, SIMONE E, SIDOTI A, TRISCHITTA F, ROMANO P: Chloride-sulphate exchange chemically measured in human erythrocyte ghosts. Cell Mol Biol 44: 351-355, 1998.

THOMAS S, EGEE S: Fish red blood cells: characteristics and physiological role of the membrane ion transporters. Comp Biochem Physiol A 119: 79-86, 1998.

WALDER JA, CHATTERJEE R, STECK TL, LOW PS, MUSSO GF, KAISER ET, ROGERS PH, ARNONE A: The interaction of hemoglobin with the cytoplasmic domain of Band 3 of the human erythrocyte membrane. $J$ Biol Chem 259: 10238-10246, 1984.

WANG T, NIELSEN OB, LYKKEBOE G: The relative contributions of red and white blood cells to whole-blood energy turnover in trout. $J$ Exp Biol 190: 43-54, 1994.

WEBER RE: Adaptations for oxygen transport: lessons from fish hemoglobins. In: Hemoglobin Function in Vertebrates: Molecular Adaptation in Extreme and Temperate Environments. DI PRISCO G, GIARDINA B, WEBER RE (eds), Springer, Milan, 2000, pp 23-37.

WEBER RE, VOELTER W, FAGO A, ECHNER H, CAMPANELLA E., LOW PS: Modulation of red cell glycolysis: interactions between vertebrate hemoglobins and cytoplasmic domains of Band 3 red cell membrane proteins. Am J Physiol 287: R454-R464, 2004.

ZIJLSTRA WG, BUURSMA A, MEEUWSEN-VAN DER ROEST WP: Absorption spectra of human fetal and adult oxyhemoglobin, deoxyhemoglobin, carboxyhemoglobin and methemoglobin. Clin Chem 37: 1633-1638, 1991. 